\title{
Differences in light response characteristics of oil peonies from eight provenances in China
}

\author{
S.Y. WEI", Q.H. LEI", W.L. JI', R. FAN, D.Y. YANG, and Y.L. ZHANG \\ College of Landscape Architecture and Arts, Northwest Agriculture and Forestry University, 712100 Yangling, \\ Shaanxi Province, China
}

\begin{abstract}
Two tree peony species, Paeonia ostii and Paeonia rockii, from eight different provenances in China (four provenances for each species) were collected for their photosynthetic characteristics. Their diurnal variations of photosynthesis, the light- and $\mathrm{CO}_{2}$-response curves and chlorophyll content were determined. Among all eight provenances, Ziwuling P. rockii had a significantly higher average daily net photosynthetic rate, showing a superior photosynthetic capacity, followed by Fengxiang $P$. ostii and Xunyang $P$. ostii. In addition, Ziwuling $P$. rockii had the highest maximum net photosynthetic rates, thus, presented a strong photosynthetic potential. Furthermore, Xunyang P. ostii, Fengxiang P. ostii, and Heze P. ostii also exhibited a great photosynthetic capacity and light adaptability, which was consistent with their high chlorophyll $a / b$ values. Taken together, Ziwuling $P$. rockii had the strongest photosynthetic capacity among all tested sources, followed by Fengxiang $P$. ostii, and Xunyang $P$. ostii, which are recommended to be used as seed sources for oil peony cultivation and cross-breeding.
\end{abstract}

Additional key words: gas exchange; leaf functional traits; photorespiration; resource acquisition; transpiration rate.

\section{Introduction}

The photosynthesis of plants is the main source of terrestrial primary production, which can reflect how well the plants can adapt to the environment. Photosynthetic parameters are an integral part of plant functional traits (Meng et al. 2019). Since plant photosynthesis mainly takes place in leaves, the functional traits of the leaves can directly affect photosynthetic rate and duration, which make them essential for the survival and reproduction of plant individuals (Kikuzawa 1991, Reich et al. 1997, Li et al. 2015). Functional traits mainly include net photosynthetic rate $\left(P_{\mathrm{N}}\right)$, respiratory rate, and stomatal conductance $\left(g_{\mathrm{s}}\right)$, which reflect the growth and metabolism index of leaves, and have relatively huge variations in terms of time and space (Zhang and Luo 2004, Liu et al. 2006, Huang et al. 2010). Plants have formed a variety of geographical provenances under the interaction with long-term climatic and geographic environments, and each source adapted to different environments differently. The morphological and physiological manifestations of the plants, which are transplanted to the same place but originated from different provenances, have always been a hot topic of research, as it is significant for exploring adaptation mechanisms of plants, especially for the study of tree response mechanism in the context of climate change.

Tree peony (Paeonia section Moutan DC) is a unique woody oil resource in China that has a strong fruit bearing ability and can be used to produce seeds and process peony seed oil (Li 2014, Zhou and Wang 2014). At the moment, Paeonia ostii 'FengDan' and Paeonia rockii are the most widely used tree peony species for oil extraction with good oil performance. The seed oil of oil peony is a new resource of edible oil approved by the Ministry of Health. The unsaturated fatty acid content is around $92.4 \%$, of which $\alpha$-linolenic acid is as high as $42.8 \%$. It is considered to be the most beneficial and healthy nutrient oil (Zhou et al. 2009, Li et al. 2012). Vigorously developing and planting oil peony can effectively alleviate the situation that more than $60 \%$ of China's edible oil has been imported (Li 2014). However, the problems of unvaried species and low yield have severely restricted the development of oil peony industry. Therefore, the introduction, domestication, and cultivation of oil peonies are extremely urgent.

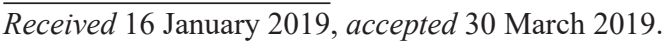

${ }^{+}$Corresponding author; e-mail:jiwenli@nwsuaf.edu.cn

Abbreviations: $\mathrm{ACE}$ - initial carboxylation efficiency; $A_{\max }$ - maximum net photosynthetic rate at $\mathrm{CO}_{2}$-saturation point; $\mathrm{AQY}$ - apparent quantum effect; $C_{\mathrm{a}}$ - air $\mathrm{CO}_{2}$ concentration; $\mathrm{CCP}-\mathrm{CO}_{2}$-compensation point; $\mathrm{Chl}$ - chlorophyll; $C_{\mathrm{i}}$ - intercellular $\mathrm{CO}_{2}$ concentration; $\mathrm{CSP}$ - saturated intercellular $\mathrm{CO}_{2}$ concentration; $E$ - transpiration rate; $g_{\mathrm{s}}$ - stomatal conductance; LCP - light-compensation point; LSP - light-saturation point; $P_{\mathrm{N}}-$ net photosynthetic rate; $P_{\mathrm{Nmax}}-$ maximum net photosynthetic rate at light-saturation point; $R_{\mathrm{D}}-$ dark respiration rate; RH - relative humidity; $R_{\mathrm{p}}$ - photorespiration rate; $t_{\mathrm{a}}$ - air temperature; VPD - vapor pressure deficit.

Acknowledgements: This study was supported by Science and Technology Project of Yangling Demonstration Zone (2017NY-16) and the Chinese Special Fund for Forest Scientific Research in the Public Welfare Program (201404701).

\#These authors contributed equally to this work.
} 
In this paper, two different species of ten-year-old peony plants from eight different provenances of China were collected. After transplanting and slowing the seedlings, the photosynthesis and physiology of different oil peony sources were analyzed by observing and measuring the leaf photosynthetic characteristics. The adaptability variances of oil peonies from different provenances to the new environment were compared, and the source of the differences was further explored from the physiological ecology perspectives. This would provide theoretical references for the future oil peony introduction and domestication, breeding of the improved species, and the response approaches as well as adaptation strategies in different environments.

\section{Materials and methods}

Overview of the test area: The test site is located in Peony Resources Garden of Northwest A\&F University, Yangling, Shaanxi, China. The area belongs to continental monsoon climate zone with an annual precipitation of $635.1 \mathrm{~mm}$, an annual average temperature of $12.9^{\circ} \mathrm{C}$, an annual average sunshine hours of $2,163.8 \mathrm{~h}$, as well as an annual accumulated temperature of $4,184^{\circ} \mathrm{C}$ for the temperature over $10^{\circ} \mathrm{C}$.

Plant materials: The test materials were fine oil peony plants selected from eight provenances, namely Heze, Yuzhong, Lintao, Liuba, Fengxiang, Shangzhou, Xunyang, and Ziwuling. Locations and climate factors of each provenance were as follows:

\begin{tabular}{|c|c|c|c|c|c|c|c|}
\hline Species & Provenance & Abbreviation & Latitude & Longitude & Altitude $[\mathrm{m}]$ & $\begin{array}{l}\text { Mean annual } \\
\text { temperature }\left[{ }^{\circ} \mathrm{C}\right]\end{array}$ & $\begin{array}{l}\text { Mean annual } \\
\text { precipitation }[\mathrm{mm}]\end{array}$ \\
\hline \multirow[t]{4}{*}{ Paeonia rockii } & Yuzhong County & PR-yz & $104^{\circ} 07^{\prime} \mathrm{E}$ & $35^{\circ} 52^{\prime} \mathrm{N}$ & 2,495 & 6.7 & 400 \\
\hline & Lintao County & PR-lt & $103^{\circ} 49^{\prime} \mathrm{E}$ & $35^{\circ} 37^{\prime} \mathrm{N}$ & 2,654 & 7.0 & 539 \\
\hline & Ziwuling Mountain & PR-zwl & $108^{\circ} 03^{\prime} \mathrm{E}$ & $35^{\circ} 20^{\prime} \mathrm{N}$ & 1,528 & 7.4 & 588 \\
\hline & Liuba County & PR-lb & $107^{\circ} 08^{\prime} \mathrm{E}$ & $33^{\circ} 42^{\prime} \mathrm{N}$ & 1,547 & 11.5 & 886 \\
\hline \multirow[t]{4}{*}{ Paeonia ostii } & Fengxiang County & PO-fx & $107^{\circ} 02^{\prime} \mathrm{E}$ & $34^{\circ} 31^{\prime} \mathrm{N}$ & 968 & 11.4 & 625 \\
\hline & Heze City & PO-hz & $115^{\circ} 45^{\prime} \mathrm{E}$ & $35^{\circ} 39^{\prime} \mathrm{N}$ & 52 & 13.8 & 663 \\
\hline & Shangzhou Area & PO-sz & $109^{\circ} 57^{\prime} \mathrm{E}$ & $33^{\circ} 52^{\prime} \mathrm{N}$ & 1,628 & 13.5 & 758 \\
\hline & Xunyang County & PO-xy & $105^{\circ} 58^{\prime} \mathrm{E}$ & $32^{\circ} 49^{\prime} \mathrm{N}$ & 846 & 14.5 & 1,050 \\
\hline
\end{tabular}

Plants were transplanted to the Peony Resource Garden of Northwest A\&F University in September 2015. The growth was stabilized after three years of slow rejuvenation, and the leaf functional traits and photosynthetic characteristics of oil peony plants were measured in the early summer season of 2018.

Diurnal variation in photosynthesis of plants from various sources was determined with a $L I-6400 X T$ portable photosynthesis measurement system (LI-COR, USA). The main measurement indexes were: net photosynthetic rate $\left(P_{\mathrm{N}}\right)$, transpiration rate $(E)$, stomatal conductance $\left(g_{\mathrm{s}}\right)$, air $\mathrm{CO}_{2}$ concentration $\left(C_{\mathrm{a}}\right)$, intercellular $\mathrm{CO}_{2}$ concentration $\left(C_{\mathrm{i}}\right)$, air temperature $\left(t_{\mathrm{a}}\right)$, relative humidity $(\mathrm{RH})$, and PAR. The test was performed on a normal sunny day, two weeks after the last leaf fertilization and measurements were taken every two hours between 8:00-18:00 h. Six plants were randomly selected from each plot, and three sunny side branches were selected from each plant, where the third leaf of the plant counting from the top was measured. The leaf chamber was a regular leaf chamber with an area of $6 \mathrm{~cm}^{2}$.

Light-response curve: The same $L I-6400 X T$ system was used for this test, where $6400-012 \mathrm{~B}$ red and blue light source was utilized, and the PAR gradient was set to 2,$000 ; 1,800$; 1,$600 ; 1,400 ; 1,200 ; 1,000 ; 800,600,400,200,150,100$, 50,20 , and $0 \mu \mathrm{mol}$ (photon) $\mathrm{m}^{-2} \mathrm{~s}^{-1}$, respectively, and the $\mathrm{CO}_{2}$ injection system value was set to $400 \mu \mathrm{mol} \mathrm{mol}{ }^{-1}$. The leaf temperature was about $26^{\circ} \mathrm{C}$ and the vapor pressure deficit (VPD) was about $2 \mathrm{kPa}$. Three plants were selected per plot, and three leaves from the same location were selected for each plant. All the leaves were subjected to light induction for $20 \mathrm{~min}$ before measurements. The apparent quantum effect (AQY), maximum net photosynthetic rate at light-saturation point $\left(P_{\mathrm{Nmax}}\right)$, dark respiration rate $\left(R_{\mathrm{D}}\right)$, light-saturation point (LSP), and light-compensation point (LCP) of each provenance treatment were calculated with the light-response model (Ye 2007, Ye and Yu 2008). The fitting equation was:

$P_{\mathrm{N}}=\alpha \times(1-\beta \times \mathrm{I}) \times \mathrm{I} /(1+\gamma \times \mathrm{I})-R_{\mathrm{D}}$,

where I refers to photosynthetically active radiation, $R_{\mathrm{D}}$ is the dark respiration rate, $\alpha$ refers to the initial slope of the light-response curve, and $\beta$ and $\gamma$ are coefficients.

$\mathrm{CO}_{2}$-response curve: The same $L I-6400 X T$ system was used for this test, where the $\mathrm{CO}_{2}$-injection system and LED red and blue light source were used, and the $\mathrm{CO}_{2}$ concentration gradient was set to 400, 300, 200, 150, $100,50,400,400,600,800 ; 1,000 ; 1,200 ; 1,500 ; 1,800$; $2,000 \mu \mathrm{mol} \mathrm{mol} \mathrm{m}^{-1}$, respectively, PAR was set to 1,500 $\mu$ mol(photon) $\mathrm{m}^{-2} \mathrm{~s}^{-1}$. The leaf temperature was about $26^{\circ} \mathrm{C}$ and VPD was about $2 \mathrm{kPa}$. The initial carboxylation efficiency (a), maximum net photosynthetic rate at $\mathrm{CO}_{2}$-saturation point $\left(A_{\max }\right)$, saturated intercellular $\mathrm{CO}_{2}$ concentration (CSP), $\mathrm{CO}_{2}$-compensation point (CCP), photorespiration rate $\left(R_{\mathrm{p}}\right)$, and coefficient of determination were calculated according to the $\mathrm{CO}_{2}$-response model (Ye and $\mathrm{Yu}$ 2009). The fitting equation was: 


$$
P_{\mathrm{N}}\left(C_{\mathrm{i}}\right)=\mathrm{a} \times\left(1-\mathrm{b} \times C_{\mathrm{i}}\right) \times C_{\mathrm{i}} /\left(1+\mathrm{c} \times C_{\mathrm{i}}\right)-R_{\mathrm{p}},
$$

where $P_{\mathrm{N}}$ is the net photosynthetic rate, $C_{\mathrm{i}}$ is the intercellular $\mathrm{CO}_{2}$ concentration, $R_{\mathrm{p}}$ is the photorespiration rate, a is the initial carboxylation efficiency of the $\mathrm{CO}_{2}$-response curve, and $\mathrm{b}$ and $\mathrm{c}$ are the coefficients.

Chlorophyll (Chl) content: $\mathrm{Chl}$ was extracted by acetone and ethanol mixture. After leaching, the spectral image of each sample was determined by using Shimadzu UV$2450 U V$-Vis (Japan) spectrophotometer. The absorbance value at 645 and $663 \mathrm{~nm}$ were selected to calculate Chl $a$, $\mathrm{Chl} b$, and total $\mathrm{Chl}$ content $[\mathrm{Chl}(a+b)]$. The results were presented in $\mathrm{mg} \mathrm{g}^{-1}$ (Porra 2002).

Data processing: Microsoft Excel 2010 was used to sort data and SPSS 20.0 was used for variance analysis (ANOVA), regression analysis, and Duncan's multiple comparison. Charts were drawn with Sigmaplot 10.0. Pearson's method was utilized to analyze the correlation between various indexes of peony leaf functional traits.

\section{Results}

Photosynthetic diurnal variation: Fig. 1 reflects the diurnal trend of the main environmental indexes that affected the leaf photosynthetic rate. During the test, the amount of PAR was lower in the morning and evening but higher during the day, reaching the maximum at noon. The $C_{\mathrm{a}}$ in the air first decreased and then increased. The plants

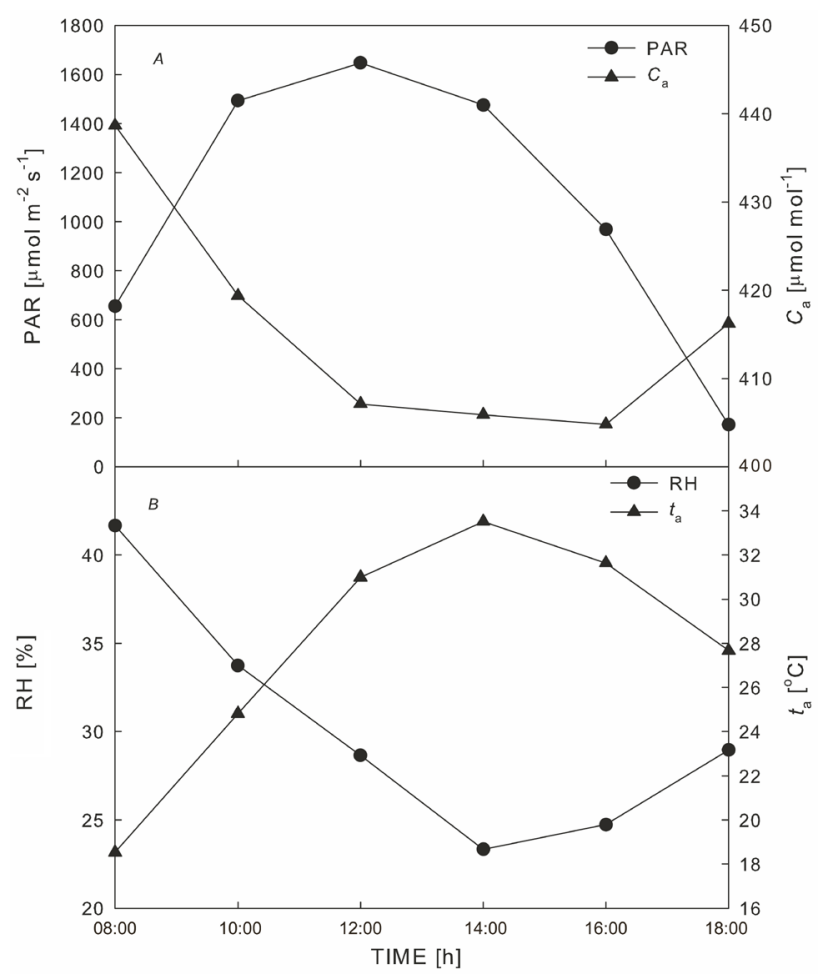

Fig. 1. Diurnal changes of photosynthetically active radiation (PAR), air $\mathrm{CO}_{2}$ concentration $\left(C_{\mathrm{a}}\right)$, air temperature $\left(t_{\mathrm{a}}\right)$, and relative humidity $(\mathrm{RH})$ during the experimental period.

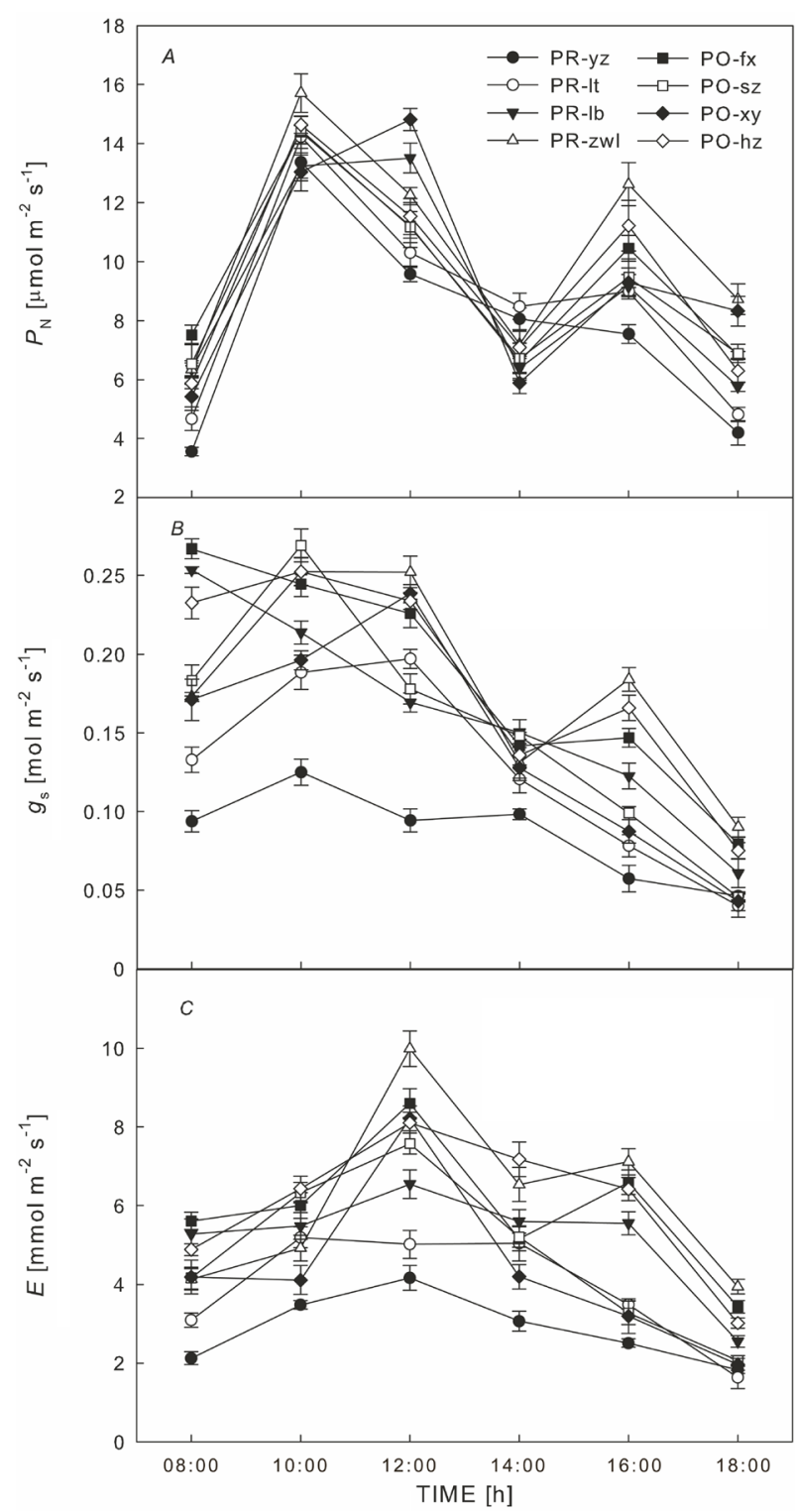

Fig. 2. Diurnal variation of net photosynthetic rate $\left(P_{\mathrm{N}}\right)(A)$, stomatal conductance $\left(g_{\mathrm{s}}\right)(B)$, and transpiration rate $(E)(C)$ of oil peonies in eight provenances.

accumulated quite a lot of $\mathrm{CO}_{2}$ after overnight respiration, and photosynthetic rate was low in the morning $\mathrm{CO}_{2}$ due to low light level so that $C_{\mathrm{a}}$ was at the highest state in the morning, with a maximum value of $438.67 \mu \mathrm{mol}$ $\mathrm{mol}^{-1}$. Then, as the light intensity increased, the rate of photosynthesis also increased. Therefore $C_{\mathrm{a}}$ gradually decreased until 16:00 $\mathrm{h}$ and increased slightly after that. Due to direct sunlight, $t_{\mathrm{a}}$ went higher with the increasing PAR, reaching a maximum of $33.8^{\circ} \mathrm{C}$ at $14: 00 \mathrm{~h}$, and then slowly decreased. However, the daily trend of RH was opposite to that of PAR and $t_{\mathrm{a}}$, i.e., dropped first and then rose. The highest level was reached at 8:00 $\mathrm{h}$ in the morning, and the lowest level occurred at 14:00 h.

Under natural conditions, the diurnal variation process of plant photosynthesis can be categorized into two types: 


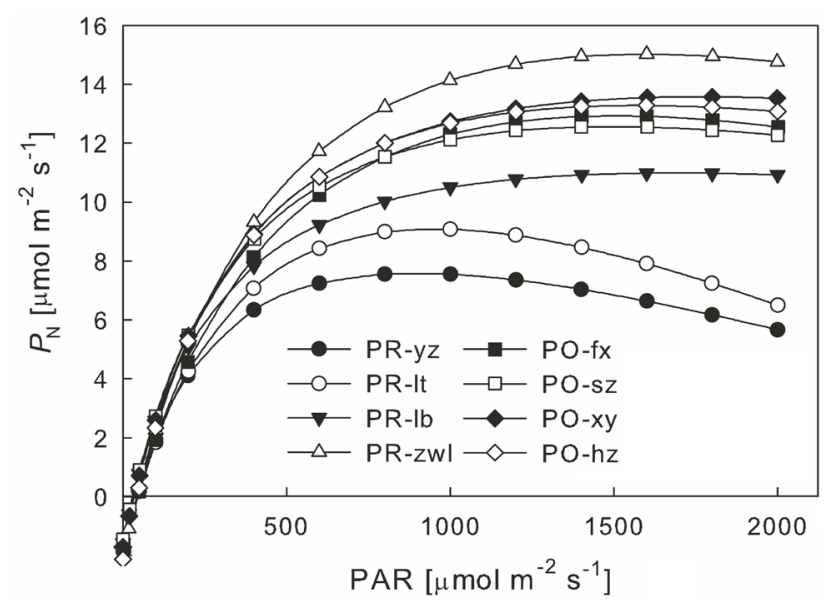

Fig. 3. Light-response curve of oil peonies in eight provenances. $\mathrm{PAR}$ - photosynthetically active radiation; $P_{\mathrm{N}}-$ net photosynthetic rate.

unimodal and bimodal. As shown in Fig. $2 A$, out of eight provenances, six of them, PO-hz, PO-fx, PO-sz, PO-xy, PR$\mathrm{lb}$, and PR-zwl, had bimodal curves for $P_{\mathrm{N}}$ daily variation. Whereas the other two, PR-yz and PR-lt, were unimodal. The bimodal curve had two distinct peaks, peak I and II, and also showed the photosynthetic an phenomenon of midday respose in leaf photosynthesis. Among the six bimodal sources, PO-hz, PO-fx, PO-sz, and PR-zwl had the peak I appeared at 10:00 h, while PO-xy and PR-lb had the peak I appeared at 12:00 h. For all the six provenances, peak II occurred at 16:00 $\mathrm{h}$, and the photosynthetic midday depression occurred at 14:00 h. Furthermore, as shown in Fig. $2 A$, the photosynthetic diurnal variation curves of PRyz and PR-lt were unimodal, and both had peaks occurred at 10:00 h. The $P_{\mathrm{N}}$ daily average of eight provenances ranging from large to small was in following order: PRzwl $>$ PO-fx $>$ PO-xy $>$ PO-hz $>$ PO-sz $>$ PR-lb $>$ PR-lt $>$ PR-yz.

The peak I values of the six peony sources with bimodal curve was ranked in descending order as: PR-zwl $>$ PO-xy $>$ PO-hz $>$ PO-sz $>$ PO-fx $>$ PR-lb. The peak I value of PR-zwl was $15.78 \mu \mathrm{mol}\left(\mathrm{CO}_{2}\right) \mathrm{m}^{-2} \mathrm{~s}^{-1}$, which was significantly higher than that of other five provenances.
The peak I values of the rest four were close to each other. In addition, the peak II values of all these six provenances were significantly lower than the peak I values.

Stomatal conductance $\left(g_{s}\right)$ refers to the ability of plant pores to conduct $\mathrm{CO}_{2}$ and water. The trend of $g_{\mathrm{s}}$ daily variation curve in different provenances is shown in Fig. $2 B$. The $g_{\mathrm{s}}$ of PO-sz, PO-hz, and PO-yz started to decrease at 10:00 h, and the $g_{\mathrm{s}}$ of PO-fx and PR-lb began to decline at 8:00 h, while in PO-zwl, PO-xy, and PRlt $g_{\text {s }}$ began to drop from 12:00 h. Only PO-hz, PR-zwl, and PO-fx showed the $g_{\mathrm{s}}$ values increased starting from 16:00 $\mathrm{h}$, the other five provenances showed a continuous decreasing trend until the end of the test.

According to Fig. $2 C$, starting from 8:00 h, the $E$ of oil peonies in all eight provenances increased with the increase of $g_{s}$. However, the magnitude of the increase varied greatly. Except for PR-lt, the $E$ of the other seven sources reached their maximum at noon and then started to drop (PR-lt was not resistant to strong light, therefore when the light reached its maximum at noon; it restrained the rate of photosynthesis and promoted stomatal closure to result in the decreasing $E$ ). The maximum transpiration rate of PR-zwl was significantly higher than that of the other provenances, indicating a higher capacity of water transport and regulation as well as a higher demand of water at this stage. The $E$ of PR-zwl and PO-fx started to increase again at $16: 00 \mathrm{~h}$, whereas other provenances continued to decrease.

Light-response curves: The light-response curve illustrates the ability of plants to adapt to changes in external light intensity. The hypervisor model was used to fit the light-response values and obtain the ideal results for the oil peonies from different provenances $\left(R^{2}=0.9982-\right.$ 0.9998; Fig. 3, Table 1). In Fig. 3, we can see that when PAR was less than $200 \mu$ mol(photon) $\mathrm{m}^{-2} \mathrm{~s}^{-1}, P_{\mathrm{N}}$ values increased linearly with the increase of light intensity, whereas when PAR was greater than $200 \mu$ mol(photon) $\mathrm{m}^{-2} \mathrm{~s}^{-1}$, the growth rate of $P_{\mathrm{N}}$ became slower, and with the light intensity increased, $P_{\mathrm{N}}$ curve gradually flattened and light was saturated at one point. The light-response curves of PR-zwl, PO-xy, PO-hz, PO-fx, PO-sz, and PR$\mathrm{lb}$ were relevantly close to each other; for all of them,

Table 1. Comparison of light-response parameters of oil peonies from eight provenances. AQY - apparent quantum efficiency; $P_{\mathrm{Nmax}}$ - maximum net photosynthetic rate at light-saturation point; LSP - light-saturation point; LCP - light-compensation point; $R_{\mathrm{D}}-$ dark respiration rate. Data represent means $\pm \mathrm{SD}$ of six independent experiments. Different letters in the same column indicate significant differences at the 5\% which are Duncan's multiple comparison test groups for one-dimensional ANOVA.

\begin{tabular}{|c|c|c|c|c|c|c|}
\hline Species & AQY & 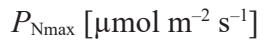 & $\operatorname{LSP}\left[\mu \mathrm{mol} \mathrm{m}{ }^{-2} \mathrm{~s}^{-1}\right]$ & $\mathrm{LCP}\left[\mu \mathrm{mol} \mathrm{m}{ }^{-2} \mathrm{~s}^{-1}\right]$ & $R_{\mathrm{D}}\left[\mu \mathrm{mol} \mathrm{m}{ }^{-2} \mathrm{~s}^{-1}\right]$ & Decisive factor \\
\hline PR-yz & $0.0530 \pm 0.0026^{\mathrm{ab}}$ & $7.59 \pm 0.50^{\mathrm{e}}$ & $894.13 \pm 51.00^{\mathrm{e}}$ & $42.89 \pm 2.59^{\mathrm{a}}$ & $1.97 \pm 0.05^{\mathrm{b}}$ & 0.9984 \\
\hline PR-lt & $0.0458 \pm 0.0027^{\mathrm{c}}$ & $9.09 \pm 0.43^{\mathrm{d}}$ & $951.38 \pm 40.79^{\mathrm{e}}$ & $45.30 \pm 2.06^{\mathrm{a}}$ & $1.87 \pm 0.08^{\mathrm{bc}}$ & 0.9982 \\
\hline PR-lb & $0.0562 \pm 0.0017^{\mathrm{a}}$ & $10.99 \pm 0.50^{\mathrm{c}}$ & $1,682.95 \pm 47.69^{b}$ & $31.88 \pm 2.51^{\mathrm{bc}}$ & $1.62 \pm 0.07^{\mathrm{de}}$ & 0.9988 \\
\hline PR-zwl & $0.0498 \pm 0.0020^{\mathrm{b}}$ & $15.02 \pm 1.06^{\mathrm{a}}$ & $1,592.17 \pm 37.32^{\mathrm{c}}$ & $43.01 \pm 2.00^{\mathrm{a}}$ & $1.99 \pm 0.14^{\mathrm{b}}$ & 0.9998 \\
\hline PO-fx & $0.0436 \pm 0.0026^{\mathrm{c}}$ & $12.93 \pm 0.57^{\mathrm{b}}$ & $1,503.89 \pm 46.66^{\mathrm{d}}$ & $44.69 \pm 2.33^{\mathrm{a}}$ & $1.81 \pm 0.08^{\mathrm{bc}}$ & 0.9983 \\
\hline PO-sz & $0.0526 \pm 0.0021^{\mathrm{ab}}$ & $12.56 \pm 0.58^{\mathrm{b}}$ & $1,487.76 \pm 40.84^{\mathrm{d}}$ & $29.93 \pm 1.68^{c}$ & $1.46 \pm 0.08^{\mathrm{e}}$ & 0.9996 \\
\hline PO-xy & $0.0540 \pm 0.0017^{\mathrm{a}}$ & $13.58 \pm 0.71^{\mathrm{b}}$ & $1,764.85 \pm 38.05^{\mathrm{a}}$ & $34.46 \pm 1.50^{\mathrm{b}}$ & $1.71 \pm 0.14^{\mathrm{cd}}$ & 0.9998 \\
\hline PO-hz & $0.0566 \pm 0.0022^{\mathrm{a}}$ & $13.28 \pm 0.69^{b}$ & $1,569.08 \pm 61.20^{\mathrm{cd}}$ & $42.87 \pm 2.51^{\mathrm{a}}$ & $2.19 \pm 0.14^{\mathrm{a}}$ & 0.9997 \\
\hline
\end{tabular}




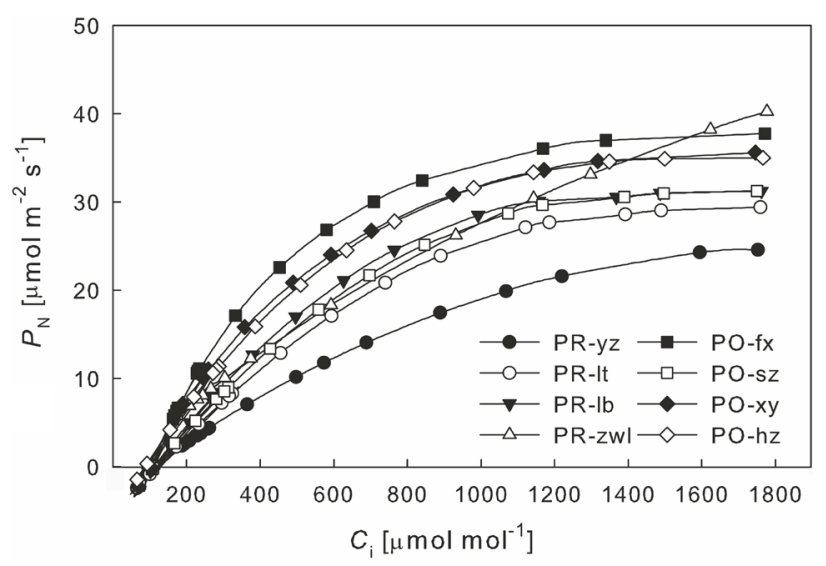

Fig. 4. $\mathrm{CO}_{2}$-response curve of oil peonies in eight provenances. $P_{\mathrm{N}}-$ net photosynthetic rate; $C_{\mathrm{i}}-$ intercellular $\mathrm{CO}_{2}$ concentration.

$P_{\mathrm{N}}$ value continued to increase when PAR ranged from 0 to $1,600 \mu \mathrm{mol}$ (photon) $\mathrm{m}^{-2} \mathrm{~s}^{-1}$, and it decreased slightly after PAR exceeded this value. The $P_{\mathrm{N}}$ value for both PRIt and PR-yz sources reached the maximum at PAR of $800 \mu \mathrm{mol}$ (photon) $\mathrm{m}^{-2} \mathrm{~s}^{-1}$, and it decreased rapidly after the PAR exceeded 1,000 $\mu$ mol(photon) $\mathrm{m}^{-2} \mathrm{~s}^{-1}$ and when photoinhibition appeared. Overall, the trend of maximum net photosynthetic rate of the eight provenances was: PRzwl $>$ PO-xy $>$ PO-hz $>$ PO-fx $>$ PO-sz $>$ PR-lb $>$ PR-lt $>$ PR-yz, indicating that PR-zwl had the greatest demand for light. Therefore, we can conclude that the oil peonies from six provenances, except for the PR-lt and PR-yz, all had a strong light adaptability. In addition, when PAR exceeded $1,000 \mu \mathrm{mol}$ (photon) $\mathrm{m}^{-2} \mathrm{~s}^{-1}$, the photo-response curves of PR-lt and PR-yz decreased sharply, indicating that strong light could weaken their photosynthetic capacity.

The AQY reflects conversion and utilization efficiency of light energy at the weak-light stage. Among the eight provenances, the AQY values of PO-hz, PR-lb, PO-xy, PR-yz, and PO-sz were relatively high and similar to each other, but they were significantly higher than that of PO-fx and PR-lt. It indicated that PO-hz, PR-lb, PO-xy, PR-yz, and PO-sz had higher light-utilization efficiency at the lowlight stage. The $P_{\text {Nmax }}$ value is a parameter characterizing the photosynthetic potential. The larger the leaf $P_{\mathrm{Nmax}}$ value, the greater is the photosynthetic potential of the plant. The $P_{\text {Nmax }}$ of PR-zwl was $15.02 \mu \mathrm{mol}\left(\mathrm{CO}_{2}\right) \mathrm{m}^{-2} \mathrm{~s}^{-1}$, which was significantly higher than all other provenances and no significant differences were observed in $P_{\text {Nmax }}$ values between provenances of PO-xy, PO-hz, PO-sz, and PO-fx. The $R_{\mathrm{D}}$ is an indicator of the respiration intensity of plant cells. High $R_{\mathrm{D}}$ indicates strong respiration expenditure in the process of photosynthetic organic synthesis, which is neither beneficial to the organic accumulation in plants nor plant growth. The $R_{\mathrm{D}}$ of PO-hz $(2.19 \mu \mathrm{mol}$ $\mathrm{m}^{-2} \mathrm{~s}^{-1}$ ) was significantly higher than in other provenances, whereas the $R_{\mathrm{D}}$ of PO-sz $\left(1.46 \mu \mathrm{mol} \mathrm{m} \mathrm{m}^{-2} \mathrm{~s}^{-1}\right)$ was by far the lowest among all the provenances. A larger LSP shows the plant preferring the sun more, while a smaller LCP indicates a higher ability to utilize the weak light as well as a stronger ability to adapt to the weak light. Among all eight provenances, the LSP of PO-xy was by far the largest, whereas the LCP of PO-sz was by far the smallest, indicating that PO-xy was a heliophilous plant and could adapt to a wider range of light intensities.

$\mathrm{CO}_{2}$-response curves: The response curve of $P_{\mathrm{N}}$ to $\mathrm{CO}_{2}$ reflects the adaptability of plants to $\mathrm{CO}_{2}$. In this experiment, the hyperbolic correction model was used to fit the $\mathrm{CO}_{2}$ response values, and the ideal result was obtained $\left(R^{2}=0.9966 \sim 0.9995 ;\right.$ Fig. 4 , Table 2$)$. Fig. 4 shows that the response tendency of $P_{\mathrm{N}}$ to the change of intercellular $\mathrm{CO}_{2}$ concentration $\left(C_{\mathrm{i}}\right)$ was similar in all provenances except for PR-zwl. With the increase of $\mathrm{CO}_{2}$ concentration, $P_{\mathrm{N}}$ gradually increased and then became stable, where $P_{\mathrm{N}}$ increased more rapidly before the $C_{\mathrm{i}}$ reached $1,000 \mu \mathrm{mol}$ $\mathrm{mol}^{-1}$, then increased slower until reached and remained at the maximum level. PO-fx had the highest $P_{\mathrm{N}}$ value compared to the other six sources at the same intercellular $\mathrm{CO}_{2}$ concentration. However, in PR-zwl, $P_{\mathrm{N}}$ continued increasing even at the maximum set value of $\mathrm{CO}_{2}$, showing a prominent adaptability and photosynthetic potential to a higher $\mathrm{CO}_{2}$ concentration.

Table 2 shows that the ACE of different provenances oil peonies differed greatly. The ACE of PO-fx was the highest and significantly higher than that of other provenances, indicating a higher utilization efficiency of $\mathrm{CO}_{2}$ at low

Table 2. Comparison of $\mathrm{CO}_{2}$-response parameters of oil peonies from eight provenances. ACE - initial carboxylation efficiency; $A_{\max }-$ maximum net photosynthetic rate at $\mathrm{CO}_{2}$-saturation point; $\mathrm{CSP}$ - saturated intercellular $\mathrm{CO}_{2}$ concentration; $\mathrm{CCP}-\mathrm{CO}_{2}$-compensation point; $R_{\mathrm{p}}$ - photorespiration rate. Data represent means $\pm \mathrm{SD}$ of six independent experiments. Different letters in the same column indicate significant differences at the 5\% which are Duncan's multiple comparison test groups for one-dimensional ANOVA.

\begin{tabular}{|c|c|c|c|c|c|c|}
\hline Species & ACE & 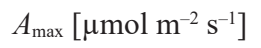 & $\mathrm{CSP}\left[\mu \mathrm{mol} \mathrm{mol}{ }^{-1}\right]$ & $\mathrm{CCP}\left[\mu \mathrm{mol} \mathrm{mol}{ }^{-1}\right]$ & $R_{\mathrm{p}}\left[\mu \mathrm{mol} \mathrm{m}{ }^{-2} \mathrm{~s}^{-1}\right]$ & Decisive factor \\
\hline PR-yz & $0.0319 \pm 0.0030^{\mathrm{g}}$ & $25.01 \pm 1.63^{\mathrm{d}}$ & $1,928.37 \pm 51.06^{\mathrm{b}}$ & $103.84 \pm 6.79^{b}$ & $3.20 \pm 0.28^{\mathrm{e}}$ & 0.9968 \\
\hline PR-lt & $0.0481 \pm 0.0031^{\mathrm{ef}}$ & $28.58 \pm 1.09^{\mathrm{d}}$ & $1,416.20 \pm 62.36^{\mathrm{d}}$ & $118.81 \pm 4.53^{\mathrm{a}}$ & $5.47 \pm 0.45^{\mathrm{d}}$ & 0.9978 \\
\hline PR-lb & $0.0605 \pm 0.0026^{\mathrm{d}}$ & $30.57 \pm 1.79^{\mathrm{cd}}$ & $1,323.56 \pm 35.68^{\mathrm{d}}$ & $110.87 \pm 7.56^{\mathrm{ab}}$ & $6.36 \pm 0.38^{c}$ & 0.9992 \\
\hline PR-zwl & $0.0401 \pm 0.0031^{\mathrm{fg}}$ & $56.31 \pm 4.13^{\mathrm{a}}$ & $2,893.73 \pm 94.93^{\mathrm{a}}$ & $73.29 \pm 3.04^{\mathrm{d}}$ & $2.76 \pm 0.11^{\mathrm{f}}$ & 0.9989 \\
\hline PO-fx & $0.1051 \pm 0.0072^{\mathrm{a}}$ & $37.75 \pm 1.56^{\mathrm{b}}$ & $1,740.54 \pm 47.25^{\mathrm{c}}$ & $105.73 \pm 5.83^{b}$ & $8.53 \pm 0.66^{\mathrm{a}}$ & 0.9966 \\
\hline PO-sz & $0.0534 \pm 0.0031^{\mathrm{de}}$ & $30.54 \pm 2.21^{\mathrm{cd}}$ & $1,392.69 \pm 46.74^{\mathrm{d}}$ & $111.74 \pm 5.90^{\mathrm{ab}}$ & $5.73 \pm 0.23^{\mathrm{cd}}$ & 0.9974 \\
\hline PO-xy & $0.0905 \pm 0.0126^{\mathrm{b}}$ & $35.58 \pm 0.52^{\mathrm{bc}}$ & $1,703.07 \pm 56.83^{\mathrm{c}}$ & $84.81 \pm 3.54^{c}$ & $7.00 \pm 0.29^{b}$ & 0.9995 \\
\hline PO-hz & $0.0734 \pm 0.0054^{c}$ & $34.45 \pm 2.15^{\mathrm{bc}}$ & $1,428.38 \pm 63.35^{\mathrm{d}}$ & $87.35 \pm 2.09^{c}$ & $6.04 \pm 0.34^{\mathrm{cd}}$ & 0.9982 \\
\hline
\end{tabular}




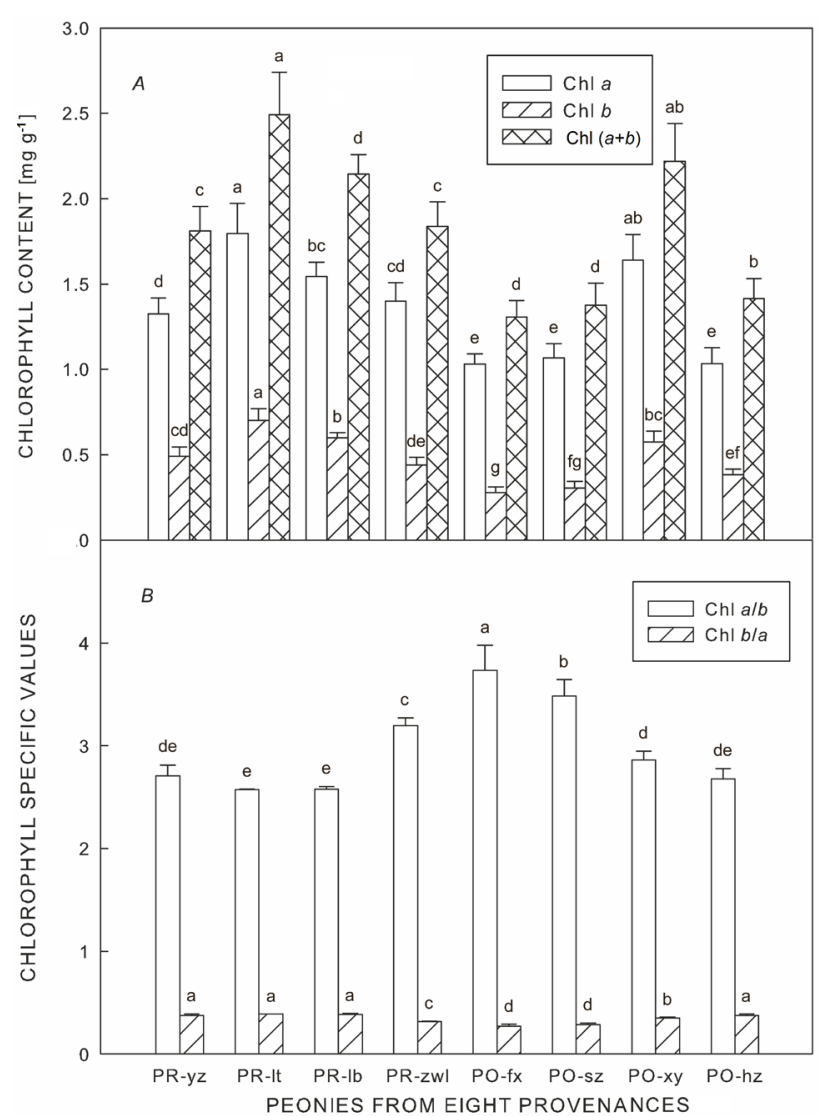

Fig. 5. The contents of chlorophyll $a(\mathrm{Chl} a)$, chlorophyll $b$ $(\mathrm{Chl} b)$, sum of chlorophyll $a$ and chlorophyll $b(\mathrm{Chl} a+b)(A)$, ratio of chlorophyll $a$ to chlorophyll $b(\mathrm{Chl} a / b)$ and ratio of chlorophyll $b$ to chlorophyll $a(\mathrm{Chl} b / a)(B)$ in oil peonies from eight provenances. Data are means of three replications and bars indicate the standard deviation of the means $(n=3)$. Different letters on the bars indicate significant differences at the 5\% which are Duncan's multiple comparison test groups for onedimensional ANOVA.

$\mathrm{CO}_{2}$ concentration, while PR-yz was the opposite. The $A_{\max }$ represents photosynthetic capacity. Among all tested sources, PR-zwl had the highest $A_{\max }$ value, highest saturated intercellular $\mathrm{CO}_{2}$ concentration, as well as the lowest $R_{\mathrm{p}}$, indicating the strongest photosynthetic capacity, adaptability to a wider range of $\mathrm{CO}_{2}$ concentrations as well as a prominent organic accumulation due to less $R_{\mathrm{p}}$ consumption.

Chl content: PR-lt had the highest contents of Chl $a, \mathrm{Chl} b$, and Chl $(a+b)$, which were $1.80,0.70,2.49 \mathrm{mg} \mathrm{g}^{-1}$, respectively (Fig. 5A). The $\mathrm{Chl} b$ content was significantly higher than that of other provenances. PR-lt had similar Chl $a$ and Chl $a+b$ contents with PO-xy, but significantly higher than that of the rest sources. PO-fx had the lowest Chl $a$, Chl $b$ and Chl $a+b$, which were $1.03,0.28,1.31$ $\mathrm{mg}^{-1}$, respectively. The descending order of Chl $a+b$ was: PR-lt $>$ PO-xy $>$ PR-lb $>$ PR-zwl $>$ PR-yz $>$ PO-hz $>$ PO-sz $>$ PO-fx. No significant differences were observed between PO-hz, PO-sz, and PO-fx. PO-fx had the highest Chl $a / b$ value of 3.73 , which was by far the highest among all sources (Fig. 5B). However, it had the lowest $\mathrm{Chl} b / a$ value, whereas PR-lt had the highest $\mathrm{Chl} b / a$ value of 0.39 . Therefore, PR-lt had the strongest shade tolerance and POfx had the weakest shade tolerance among the eight tested provenances.

\section{Discussion}

During the long process of evolution and development, plants have interacted with the environment and gradually formed morphological and physiological structures that can adapt to the external environment changes, mainly reflecting in the differences of leaves, roots, seeds, and other plant characteristics (Violle et al. 2007). Leaf photosynthesis is one of the most important physiological traits within plant leaf functional traits, which is related to crop growth and yield (Song et al. 2012, Rao et al. 2018). The net photosynthetic rate reflects the abilities of $\mathrm{CO}_{2}$ fixation and organic matter accumulation (Song et al. 2013), and the relationship between net photosynthetic rate and yield has been controversial. Some researchers think that there is a positive correlation between the two (Medrano et al. 2003, Velička et al. 2007, Liu et al. 2017), and it is possible to breed high-yield varieties by increasing the net photosynthetic rate of single leaves. Others believe the two are negatively correlated, and the relationship between net photosynthetic rate and yield in different periods may also be inconsistent (Zhang et al. 2011). In fact, the yield is essentially determined by the photosynthetic capacity and photosynthetic rate of the leaves. The results of this study showed that the daily average $P_{\mathrm{N}}$ value of PR-zwl was significantly higher than that of other provenances under natural conditions, indicating a stronger photosynthetic capacity. At the same time, according to the morning peak of the net photosynthetic rate, the peak I of PR-zwl was also significantly higher than that of other sources. Since the photosynthetic rate is a heritable plant trait, we can conclude that PR-zwl has the strongest photosynthetic capacity among the eight oil peony provenances, followed by PO-fx, PO-xy, PO-hz, and PO-sz.

Stomata are the channels for gas exchange between plants and the external environment for $\mathrm{CO}_{2}, \mathrm{O}_{2}$, and $\mathrm{H}_{2} \mathrm{O}$. The size of the pore diameter directly determines the strength of plant leaf transpiration and the rate of photosynthesis, which in turn affects material accumulation rates. Studies showed that there is a feedback regulation between the $\mathrm{CO}_{2}$ concentration and the stomatal conductance in the inferior stomatal space (Betzelberger et al. 2010). A decrease in photosynthetic rate may be due to stomatal limitation or a decrease in photosynthetic capacity of mesophyll tissue (Hetherington and Woodward 2003), where both induced factors can be affected by environmental conditions (Chen et al. 2002). In this study, six of the eight oil peony's diurnal variations of photosynthesis curves were bimodal. The first decrease of $P_{\mathrm{N}}$ value occurred between the peak I and 14:00 h, which was caused by the decrease of stomatal conductance, whereas the second $P_{\mathrm{N}}$ value decrease after the peak II was caused by the decrease in photosynthetic capacity of the leaf mesophyll tissue. Temperature and transpiration rate might be the causes that peak I occurred 
at different times for different oil peony sources.

The light-response curve and $\mathrm{CO}_{2}$-response curve can reflect the plant adaptability to changes in light intensity and $\mathrm{CO}_{2}$ concentration, they can also reflect the potential photosynthetic capacity of the plants. They can be affected by various factors, such as Chl quantity and respiration rate. In this study, the fitting correlation coefficient of light-response value and $\mathrm{CO}_{2}$-response value of oil peony was relatively high, which well reflected the differences of the net photosynthetic rate change between different oil peony sources under various light conditions and $\mathrm{CO}_{2}$ concentrations. Both LCP and LSP can be used as indicators to evaluate plant's light energy utilization ability. A smaller LCP value shows higher plant utilization ability for weak light, whereas a larger LSP value means higher utilization ability of strong light. Among eight tested sources, POxy had significantly the highest LSP value, indicating a heliophilous plant with a stronger ecological adaptability to light than that of other provenances. The LCP of PO-sz was significantly lower than of other provenances, indicating a higher ability to utilize weak lights. A small LSP value and a large LCP value means a narrower utilization range of light. AQY is a way to measure the maximum efficiency of light energy conversion in photosynthesis. It can correctly reflect the changes of the organization and function of the photosynthetic apparatus, as well as the ability for leaves to use weak light. AQY value is positively correlated with the amount of the pigment-protein complexes for absorbing and converting light energy and the ability to utilize weak light. The study showed that PO-hz, PR-lb, PO-xy, PR$\mathrm{yz}$, and PO-sz had higher light-utilization efficiency at the low-light stage. $P_{\text {Nmax }}$ and $A_{\max }$ values are parameters for characterizing photosynthetic potential (Farquhar and Sharkey 1982, Cai et al. 2012). The larger the leaf $P_{\text {Nmax }}$ and $A_{\max }$ values, the greater the photosynthetic potential of the plant. PR-zwl had the largest $P_{\mathrm{N} \max }$ and $A_{\max }$ values among all eight tested sources, therefore the greatest photosynthetic capacity.

Chl is the main pigment that absorbs light energy during plant photosynthesis (Xiong et al. 2012). Chl content is a critical reference parameter for the quantitative calculation of plant physiological responses (Watling et al. 2000). It is also an important factor in determining photosynthetic rate and the total dry matter accumulation (Maxwell and Johnson 2000). Its content directly affects the plant photosynthetic ability. In general, the shade-tolerant plants usually have a relatively high Chl $b$ content (Wittmann et $a l$. 2001). The ratio of $\mathrm{Chl} a / b$ reflects the percentage of light-harvesting pigment complex II in all Chl-containing structures, where higher ratio indicates a stronger lightharvesting ability. In this study, PO-fx, PO-sz, and PRzwl had relatively higher $\mathrm{Chl} a / b$ value, indicating higher utilization rates of light energy. Studies showed that walnuts had higher Chl $b / a$ values under shading than under light conditions (Garty et al. 2001), Chl b/a values of PR-lt and PR-yz were relatively high but they had lower net photosynthetic rate as well as a lower tolerance of strong light, showing a strong shade tolerance.

In this study, the leaf structure characteristics and yield results were not incorporated in the photosynthetic characteristics of oil tree peony experiment. They will be investigated in the future studies.

Conclusion: According to the positive correlation between photosynthesis and yield, combined with the response strategies of oil peonies from different provenances to environmental changes, we were able to predict the bearing capacity and adaptability of different provenances, and to filter out the optimal oil peony provenance. The results showed that PR-zwl, PO-fx, and PO-xy had relatively strong advantages in photosynthesis and outstanding adaptability to the environment. Therefore, they can be used as excellent provenances for oil peony cultivation and the parents for hybrid breeding of oil peony.

\section{References}

Betzelberger A.M., Gillespie K.M., McGrath J.M. et al.: Effects of chronic elevated ozone concentration on antioxidant capacity, photosynthesis and seed yield of 10 soybean cultivars. - Plant Cell Environ. 33: 1569-1581, 2010.

Cai Q.S., Wang L.L., Yao W.H. et al.: Diallel analysis of photosynthetic traits in maize. - Crop Sci. 52: 551-559, 2012.

Chen G.Y., Liao Y., Cai S.Q. et al.: [Leaf photosynthetic acclimation of Echinochloa crusgalli grown in rice field to free-air $\mathrm{CO}_{2}$ enrichment (FACE).] - Chin. J. Appl. Ecol. 13: 1201-1204, 2002. [In Chinese]

Farquhar G.D., Sharkey T.D.: Stomatal conductance and photosynthesis. - Ann. Rev. Plant. Physio. 33: 317-345, 1982.

Garty J., Tamir O., Hassid I. et al.: Photosynthesis, chlorophyll integrity, and spectral reflectance in lichens exposed to air pollution. - J. Environ. Qual. 30: 884-893, 2001.

Hetherington A.M., Woodward F.I.: The role of stomata in sensing and driving environmental change. - Nature 424: 901-908, 2003.

Huang W.J., Li Z.J., Yang Z.P., Bai G.: [The structural traits of Populus euphratica heteromorphic leaves and their correlations.] - Acta Ecol. Sin. 30: 4636-4642, 2010. [In Chinese]

Kikuzawa K.: A cost-benefit analysis of leaf habit and leaf longevity of trees and their geographical pattern. - Am. Nat. 138: 1250-1263, 1991.

Li K., Zhou N., Li H.Y.: [Composition and function research of peony flowers and peony seeds.] - Food Res. Dev. 33: 228230, 2012. [In Chinese]

Li L., McCormack M.L., Ma C. et al.: Leaf economics and hydraulic traits are decoupled in five species-rich tropicalsubtropical forests. - Ecol. Lett. 18: 899-906, 2015.

Li Y.C.: [The strategy on the oil tree peony industry in China.] Eng. Sci. 16: 58-63, 2014. [In Chinese]

Liu G.F., Liu Y.P., Baiyila D. et al.: [Leaf traits of dominant plants of main forest communities in Daqinggou Nature Reserve.] Acta Ecol. Sin. 37: 4646-4655, 2017. [In Chinese]

Liu J.H., Zeng D.H., Lee D.K.: [Leaf traits and their interrelationships of main plant species in southeast Horqin sandy land.] - Chin. J. Ecol. 25: 921-925, 2006. [In Chinese]

Maxwell K., Johnson G.N.: Chlorophyll fluorescence - a practical guide. - J. Exp. Bot. 51: 659-668, 2000.

Medrano H., Escalona J.M., Cifre J. et al.: A ten-year study on the physiology of two Spanish grapevine cultivars under field conditions: effects of water availability from leaf photosynthesis to grape yield and quality. - Funct. Plant Biol. 30: 607-619, 2003.

Meng C.J., Liu X., Chai Y.F. et al.: Another choice for measuring tree photosynthesis in vitro. - PeerJ 7: e5933, 2019. 
Porra R.J.: The chequered history of the development and use of simultaneous equations for the accurate determination of chlorophylls $a$ and $b$. - Photosynth. Res. 73: 149-156, 2002.

Rao Y.V., Balakrishnan D., Addanki K.R. et al.: Characterization of backcross introgression lines derived from Oryza nivara accessions for photosynthesis and yield. - Physiol. Mol. Biol. Pla. 24: 1147-1164, 2018.

Reich P.B., Walters M.B., Ellsworth D.S.: From tropics to tundra: Global convergence in plant functioning. - P. Natl. Acad. Sci. USA 94: 11373-13730, 1997.

Song G., Wen Z.M., Zheng Y. et al.: [Relationships between plant functional traits of Robinia pseudoacacia and meteorological factors in Loess Plateau, North Shaanxi, China.] - Res. Soil Water Conserv. 20: 125-130, 2013. [In Chinese]

Song H., Gao J.F., Gao X.L. et al.: Relations between photosynthetic parameters and seed yields of adzuki bean cultivars (Vigna angularis). - J. Integr. Agr. 11: 1453-1461, 2012.

Velička R., Martsinkyavichené A., Rimkevichené M.: Photosynthetic characteristics and productivity of spring rape plants as related to crop density. - Russ. J. Plant Physl+ 54: 545-552, 2007.

Violle C., Navas M.L., Vile D. et al.: Let the concept of trait be functional! - Oikos 116: 882-892, 2007.

Watling J.R., Press M.C., Quick W.P.: Elevated $\mathrm{CO}_{2}$ induces biochemical and ultrastructural changes in leaves of the $\mathrm{C}_{4}$ cereal sorghum. - Plant. Physiol. 123: 1143-1152, 2000.

Wittmann C., Aschan G., Pfanz H.: Leaf and twig photosynthesis of young beech (Fagus sylvatica) and aspen (Populus tremula) trees grown under different light regime. - Basic Appl. Ecol. 2: 145-154, 2001.

Xiong C.Y., Zeng W., Xiao F.M. et al.: [An analysis of photosynthetic parameters among Schima superba provenances.] Acta Ecol. Sin. 32: 3628-3634, 2012. [In Chinese]

Ye Z.P.: A new model for relationship between irradiance and the rate of photosynthesis in Oryza sativa. - Photosynthetica 45: 637-640, 2007.

Ye Z.P., Yu J.: [A comparison of response curves of winter wheat photosynthesis to flag leaf intercellular and air $\mathrm{CO}_{2}$ concentrations.] - Chin. J. Ecol. 28: 2223-2233, 2009. [In Chinese]

Ye Z.P., Yu Q.: A coupled model of stomatal conductance and photosynthesis for winter wheat. - Photosynthetica 46: 637 640, 2008.

Zhang J.F., Zhu Y.S., Cai Q.H. et al.: [Analysis on correlationship of net photosynthetic rate with yield and its components of ratooning rice.] - Chin. J. Rice Sci. 25: 103-106, 2011. [In Chinese]

Zhang L., Luo T.X.: [Advances in ecological studies on leaf lifespan and associated leaf traits.] - Acta Phytoecol. Sin. 28: 844-852, 2004. [In Chinese]

Zhou H.M., Ma J.Q., Miao C.Y. et al.: [Physicochemical indexes and fatty acid composition of peony seed oil.] - China Oil. Fat. 34: 72-74, 2009. [In Chinese]

Zhou L., Wang Y.: [Development and utilization of oil seed peony and its industrial development strategy in China.] World Forest. Res. 27: 68-71, 2014. [In Chinese]

(C) The authors. This is an open access article distributed under the terms of the Creative Commons BY-NC-ND Licence. 